\title{
Ciência aberta em entrevistas e em sociodramas - a Revista Brasileira de Psicodrama torna-se REVISTA VIVA
}

\author{
Fleury, Heloisa Junqueira ${ }^{1^{*}}$ \\ Kim, Leila Maria Vieira ${ }^{2 * *}$ \\ ${ }^{1}$ Pesquisadora autônoma - Brasil \\ ${ }^{2}$ Universidade de Aveiro - Portugal \\ ORCID ID: https://orcid.org/0000-0001-5084-8390* \\ ORCID ID: https://orcid.org/0000-0003-4814-7557**
}

\begin{abstract}
Resumo
Objetivo: Descrever a experiência da REVISTA VIVA como periódico de ciência aberta posterior à publicação. Metodologia: Descritiva de encontros on-line, como entrevistas com os autores de dois ou três artigos com maior número de visualizações no site da Revista (plataforma OJS), conduzidas pelo editor de seção e pareceristas; sociodramas em várias etapas para apresentação e discussão dos artigos do exemplar e sociodramas temáticos, com foco nas ressonâncias do sociodrama anterior, de apresentação dos artigos. Resultados: avaliação pelo número de acessos no website da Revista. Conclusão: Essa iniciativa pode ser uma ação motivadora para se implementar a revisão aberta na Revista Brasileira de Psicodrama.

Palavras-chave: Ciência Aberta. Sociodrama. Entrevista.
\end{abstract}

\section{Open science in interviews and sociodramas - the Revista Brasileira de Psicodrama becomes REVISTA VIVA}

\begin{abstract}
Objective: Describe the experience of REVISTA VIVA as an open science journal after publication. Methodology: Descriptive of on-line sessions, interviews with authors of two or three articles with the highest number of views on the journal's website (OJS platform), conducted by the section editor and reviewers; sociodramas for presentation and discussion of articles of the issue and thematic sociodramas, focusing on the resonances of previous sociodrama of articles presentation. Results: evaluation by the number of views of the Journal's website. Conclusion: This initiative can be a motivating action to implement the open review in the Revista Brasileira de Psicodrama.
\end{abstract}

Keywords: Open Science. Sociodrama. Interview.

\section{Ciencia abierta en entrevistas y sociodramas - Revista Brasileira de Psicodrama se convierte en REVISTA VIVA}

\section{Resumen}

Objetivo: Describir la experiencia de REVISTA VIVA como una revista de ciencias abiertas después de la publicación. Metodología: Descriptivo de sesiones en línea, entrevistas con los autores de dos o tres artículos con el mayor número de puntos de vista en la página web de la revista (plataforma OJS), realizadas por el editor de la sección y revisores; sociodramas para la presentación y discusión de los artículos del ejemplar y sociodramas temáticos, centrándose en las resonancias del sociodrama de presentación de los artículos. Resultados: evaluación por el número de puntos de vista en el sitio web de la Revista. Conclusión: Esta iniciativa puede ser una acción motivadora para implementar la revisión abierta en la Revista Brasileira de Psicodrama.

Palabras clave: Ciencia Abierta. Sociodrama. Entrevista. 


\section{Introdução}

A Revista Brasileira de Psicodrama é um periódico de acesso aberto, quadrimestral, da Federação Brasileira de Psicodrama (Febrap), que vem sendo editada regularmente desde 1994. Divulga as novas tendências do movimento psicodramático nacional e internacional, estimulando a reflexão e o debate sobre o psicodrama inserido no contexto científico, cultural, social e político contemporâneo.

Apesar do reconhecimento científico pela comunidade psicodramática brasileira e internacional, o periódico tem encontrado dificuldade para indexação em bases de dados internacionais, com o argumento de que os artigos publicados são pouco citados em determinadas bases, nas quais a Revista tem interesse em ser indexada. Esse fato confirma a tendência observada entre os autores de citarem livros em uma porcentagem acima do recomendado.

Nos últimos anos, algumas iniciativas foram tomadas com o intuito de divulgar a Revista e por consequência atrair autores e citações dos artigos, tais como informações em congressos e em outros espaços de reunião dos representantes das instituições formadoras de Psicodrama, estímulos para acesso aos artigos, apresentação em blogs da Associação Brasileira de Editores Científicos (ABEC), publicação em preprint (Emeri), além de divulgação em página da Revista no Facebook e no Instagram.

Nesse contexto, foi elaborado o projeto Revista Viva, um programa com duas modalidades de eventos on-line. A primeira modalidade consta de entrevistas com os autores dos artigos mais acessados, inaugurando um modelo de revisão aberta após a publicação. A Ciência Aberta revela os participantes do processo de avaliação, incluindo os editores de seção e pareceristas como entrevistadores.

Torna-se uma oportunidade de confraternização com todos os atores do processo de avaliação e publicação do artigo: o autor pode agradecer à equipe que o ajudou a melhorar o artigo, os pareceristas podem compartilhar a satisfação por ter contribuído na publicação de um bom artigo, assim como as dificuldades e solidão do papel, e os editores de seção podem promover essa confraternização ao vivo, deixando de ser o detentor de identidades impedidas da vivência dessa celebração final. ${ }^{1}$

A segunda modalidade de eventos visa aumentar o número de acessos aos artigos. A apresentação dos artigos ocorre por meio da metodologia ativa, que promove a aprendizagem em contexto lúdico. O sociodrama, principal método ativo do psicodrama, foi adaptado para criar on-

${ }^{1}$ Link para a primeira entrevista do projeto https://www.facebook.com/Revbraspsicodrama/videos/742162823183940. 
line a Revista Viva, com as apresentações pelos autores do conteúdo dos artigos, seguidas de discussões e dramatizações que sintetizam o conteúdo dos artigos. Em evento posterior, o sociodrama é novamente utilizado para facilitar a construção compartilhada do conhecimento coletivo emergente da experiência anterior.

Por meio dessas duas modalidades de intervenção, o projeto Revista Viva tem como objetivo descrever a experiência Revista Viva como periódico de ciência aberta posterior à publicação.

\section{Metodologia}

A metodologia desse trabalho é descritiva. A REVISTA VIVA é um retrato falado da produção científica de psicodramatistas e afins, que apresenta um exemplar por mês, em eventos semanais, aos sábados, às 17:30h, sempre no mesmo link do Zoom.

Para a sua realização foram utilizados os seguintes procedimentos:

A. Entrevistas on-line com os autores de dois ou três artigos mais acessados de determinado exemplar da Revista. Ocorrem no segundo, quarto e, ocasionalmente, no quinto sábado de cada mês.

A escolha dos artigos é feita entre aqueles que apresentam o maior número de visualizações, apontado pelos relatórios das estatísticas apresentadas no site da revista, ${ }^{2}$ que utiliza a plataforma OJS. As entrevistas são conduzidas pelo editor de seção responsável pelo artigo.

A Revista Brasileira de Psicodrama está empenhada em acompanhar as melhores práticas da Ciência Aberta e, para isso, convida os pareceristas para essa entrevista, desde que eles e os autores concordem.

B. Sociodramas on-line. No primeiro sábado do mês, apresentação dos artigos on-line e, no terceiro sábado, sociodramas temáticos, para construir o foco em ressonâncias do anterior.

O sociodrama é o método do psicodrama mais utilizado para o trabalho com grupos. Favorece a inclusão de todos os participantes e o aprofundamento no tema coletivo emergente no grupo. Tem sido adaptado para o ambiente virtual, por meio da plataforma Zoom (RODRIGUES et al., 2020; CASTRO et al., 2020).

As etapas do sociodrama de apresentação dos artigos (exemplar vol.27, n.2, 2019), ocorrido no primeiro sábado de setembro (05/09/2020), com 2 horas de duração, estão descritas a seguir.

Etapa 1 - abertura do evento.

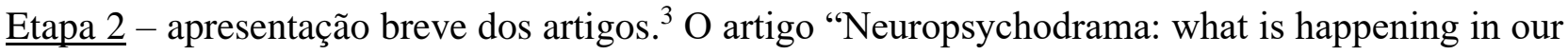
brains in psychodrama?", de Esra Bilik, do Istanbul Psychodrama Institute (Turquia), não foi

\footnotetext{
${ }^{2}$ https://revbraspsicodrama.org.br/rbp/issue/archive

${ }^{3}$ Disponíveis em: https://revbraspsicodrama.org.br/rbp/issue/view/1 
incluído porque foi decidido conjuntamente com a autora a exclusividade do idioma português nesse projeto.

Etapa 3 - divisão do grupo em 5 subgrupos aleatórios com duração de 25 minutos. Cada subgrupo é coordenado por autores de 2 artigos, selecionados pela diretora segundo o critério de temas ou contextos similares. Os autores coordenam as discussões sobre o conteúdo dos artigos. A divisão aleatória visa garantir que todos os artigos recebam o mesmo número de participantes, que poderão ampliar a sua percepção sobre os conteúdos apresentados. Cada subgrupo deverá se preparar para uma apresentação de 3 minutos do resultado das discussões na próxima etapa.

Etapa 4 - Os subgrupos são direcionados para o grande grupo novamente. Nessa etapa, cada subgrupo apresenta o resultado das discussões por meio de dramatizações, com duração de 30 minutos.

$\underline{\text { Etapa } 5}$ - compartilhamento da experiência vivida entre todos os presentes, com duração de 20 minutos.

Etapa 6 - fechamento do sociodrama com análise e considerações finais.

\section{Resultados e Discussão}

Os resultados obtidos com essa metodologia estão sendo avaliados pelo número de acessos ao website da Revista. Os sociodramas de dois exemplares, ocorridos nos meses de agosto e setembro de 2020, apresentaram resultados bastantes promissores, porque motivaram os participantes para conhecerem mais e melhor as etapas do método científico, bem como os conteúdos dos artigos. No período de lançamento do projeto, os acessos ao website da Revista tiveram um aumento de $31 \%$.

Foram realizadas duas entrevistas em ciência aberta após publicação, que ampliaram a percepção dos bastidores da escrita dos artigos mais acessados, bem como da forma de fazer os recortes das pesquisas realizadas. Porém, os dados poderão ser corretamente avaliados apenas ao final dos 4 meses de implantação do programa.

\section{Considerações finais}

O maior desafio para a Revista Brasileira de Psicodrama é continuar melhorando sua avaliação para conquistar novas indexações. A aplicação do método psicodramático mais popular na conquista desses novos espaços confirma a versatilidade do psicodrama e a multiplicidades de contextos para aplicação desse método. 
Nos encontros, a relação parecerista-autor é muito rica e prazerosa, com compartilhamento de experiências pessoais e desafios ao longo do processo. Essa iniciativa pode ser uma ação motivadora para se implementar a revisão aberta, que atualmente deixa os autores constrangidos em terem seus textos expostos e os pareceristas desconfortáveis em opinar de forma pública.

\section{Referências}

CASTRO, Amanda; VIDAL, Gabriela Pereira; SILVEIRA, Bruno da Silva da; OLIVEIRA, Daniela Cardoso de (2020). The SURVIVAL through on-line Sociodrama: Covid19, what do you want to tell me? (preprint submitted to: Revista Brasileira de Psicodrama). EmeRI - Emerging Research Information. DOI: 10.21452/2318-04982020001. Disponível em: https://preprints.ibict.br/handle/1618034/38. Acesso em: 03 set. 2020.

RODRIGUES, Rosane; COUTINHO, Eduardo Tessari; BAREAA, Janaína Cristina; OLIVEIRA E AGUIAR, Alexandre de. Telepresencial Reprise Theater in COVID-19 times. Revista Brasileira De Psicodrama, v. 28, n. 2, p.142-153, 2020. Disponível em:

https://revbraspsicodrama.org.br/rbp/article/view/427. Acesso em: 03 set. 2020.

$1{ }^{1}$ Heloisa Junqueira Fleury (São Paulo, São Paulo, Brasil)
Psicóloga clínica e mestre pela Faculdade de Medicina da Universidade de São Paulo (FMUSP). Editora da Revista
Brasileira Psicodrama. Membro do Conselho Deliberativo da ABEC. Organizadora de livros e autora de capítulos
e publicações em revistas científicas brasileiras e internacionais.
Contribuição de autoria: Administração do Projeto, Análise Formal, Conceituação, Metodologia, Escrita -
Primeira Redação e Escrita - Revisão e Edição.
Lattes: http://lattes.cnpq.br/1957423796429507
E-mail: $\underline{\text { hjfleury@ @ol.com.br }}$

\section{${ }^{2}$ Leila Maria Vieira Kim (São Paulo, São Paulo, Brasil)}

Pós-Doutorado em Estudos Culturais pela Universidade de Aveiro - Portugal e Educação UNINOVE -SP, Doutora em Psicologia Clínica Universidade de São Paulo, Mestre em Psicologia da Educação PUC-SP, Editora de Seção (Educação) da Revista Brasileira de Psicodrama. Organizadora, editora e autora de livros e artigos nacionais e internacionais.

Contribuição de autoria: Administração do Projeto, Conceituação, Investigação, Metodologia e Escrita - Revisão e Edição.

Lattes: http://lattes.cnpq.br/9133658459617524

E-mail: leilakim.animus@gmail.com

Avaliador(a) responsável: Eli Lopes da Silva

\section{Como citar este artigo:}

FLEURY, Heloisa Junqueira, KIM, Leila Maria Vieira. Ciência aberta em entrevistas e em sociodramas - a Revista Brasileira de Psicodrama torna-se REVISTA VIVA. In: ABEC Meeting Live, 2020. Anais... São Paulo: Associação Brasileira de Editores Científicos, 2020. DOI: http://dx.doi.org/10.21452/abecmeeting2020.05 